\title{
Beneficial Effect of Yoga-based Lifestyle Intervention on Anxiety and Depression in Young adults: Non-randomized Controlled Study
}

\author{
Singh Deepeshwar*, Dilip Kumar
}

\begin{abstract}
Background and Aim: Regular yoga practices have been shown beneficial effects on physical, psychological and social health in clinical and non-clinical population. The aim of the present study was to investigate the effect of yoga based lifestyle intervention on anxiety, depression and quality of life in young adults. Methods and Materials: Total 102 participants of both genders (40 females) between 25-45 years who reported anxiety and depression in last six months. There were fifty-two participants enrolled for yoga therapy (YT) for two weeks whereas 50 participants selected from nearby clinic. The anxiety and depression were assessed by using the Hospital Anxiety and Depression Scale (HADS) and general health was assessed by the General Health Questionnaire (GHQ). Results and Conclusion: Statistical analysis showed that anxiety and depression were significantly reduced by $23 \%$ and $32 \%$ respectively, whereas general health (GHO) was improved by $15 \%$ after 14-day yoga intervention. This suggests that yoga based lifestyle intervention may be a cost-effective add-on treatment for symptoms associated with mental health problems and enhances general wellbeing.

Key words: Yoga, Integrated approach of yoga therapy, Hospital Anxiety and Depression Scale, General Health Questionnaire-12, Anxiety, Depression.

Key Messages: Yoga is the best combination of physical postures for physical health, breathing practices for mental and social health and meditation practices for internal peacefulness and happiness in our life. Yoga can be practiced by school children, college students, corporate executives and old age people.
\end{abstract}

\section{Singh Deepeshwar*, Dilip Kumar}

Department of Yoga and Life Sciences, Swami Vivekananda Yoga Anusandhana Samsthana (S-VYASA), Bangalore, Karnataka, INDIA.

\section{Correspondence}

\section{Dr. Deepeshwar Singh}

Associate Professor, Swami Vivekananda Yoga Aunsandhana Samsthana (S-VYASA), Eknath Bhavan, Gavipuram Circle, K.G. Nagar-560105, Bangalore, Karnataka, INDIA.

Email: deepeshwar.singh@outlook.com

\section{History}

- Submission Date: 25-10-2021

- Revised Date: 28-11-2021

- Accepted Date: 17-12-2021

DOI : 10.5530/ijmedph.2022.1.3

Article Available online

http://www.ijmedph.org/v12/i1

\section{Copyright}

(c) 2022 Phcog.Net. This is an openaccess article distributed under the terms of the Creative Commons Attribution 4.0 International license.

\section{INTRODUCTION}

Every individual commonly experiences anxiety and depression at some point or the other in life. These are the most prevalent mental health problems faced by young adults because of sedentary lifestyle, ${ }^{1,2}$ interpersonal ${ }^{3}$ or intrapersonal conflicts ${ }^{4}$ and social challenges. ${ }^{5}$ Coleman has defined as "anxiety is an internalized fear aroused by an impulse to commit mistakes". ${ }^{6}$ The common symptoms of anxiety are stomach aches, increased heart rate, shortness of breath, sweating from palms and feet's, trembling, ${ }^{7}$ etc. In contrast to anxiety, another major mental disorder is depression, characterized by sadness, loss of interest, laziness, feelings of guilt or low selfworth, poor quality of sleep, poor appetite, feeling of tiredness, poor attention and concentration, ${ }^{8}$ etc. Coleman is defined as "depression is an emotional state characterized by extreme dejection, gloomy ruminations, feeling of worthlessness, loss of hope and often of apprehension". ${ }^{\prime}$

Recent literature reported that the prevalence of depression in one among every twenty people suffers and females are much higher (around 9.5\%) than males $(5.8 \%)$. The depression rate in young adults and adolescents has estimated ranges between

Cite this article : Deepeshwar S, Kumar D. Beneficial Effect of Yoga-based Lifestyle Intervention on Anxiety and Depression in Young adults: Non-randomized Controlled Study. Int J Med Public Health. 2022;12(1):12-9. 
participants, and who had minimum one-year of yoga experience. ${ }^{28}$ The aforementioned finding suggests that yoga intervention has a greater impact on the symptoms of anxiety and depression in different ageranged population. . $^{192,25,29-31}$

However, above mentioned studies reported the long-term effect of yoga (> 2 to 6 months) on anxiety and depression in college students, older people or either in female or male subjects separately. In addition to this, these groups are either received particular technique of yoga such as yoga postures, ${ }^{26}$ breathing practices, ${ }^{30,32}$ relaxation $^{33}$ and meditation. ${ }^{1734-37}$ Some other studies assessed the collective effect of breathing and meditation on anxiety and depression. ${ }^{38}$ Very few studies evaluated the integrated approach to yoga practice that includes yogasana, pranayama, relaxation techniques, and meditation, in patients suffering from both anxiety and depression. Therefore, in the present study, we intended to assess the effect of yoga based lifestyle intervention for two weeks on young adults who diagnosed with anxiety and depression.

\section{MATERIALS AND METHODS}

\section{Participants}

The recruitment of participants in the study is given in Figure 1. A total of 102 participants ages ranging between 25-45 years (group averaged age \pm SD; $35.01 \pm 9.7$ years; 40 females) who reported anxiety and depression in last six months. These participants were recruited from a Yoga therapy center and stress and lifestyle clinics, South India. There were fifty-two participants (group averaged age \pm SD; $33.2 \pm 6.4$ years; 16 females) enrolled for yoga therapy (YT) for two weeks whereas fifty participants ( $34.6 \pm 8.7$ years; 24 females) selected from a nearby clinic. All potential participants were screened by a qualified psychiatrist using mini-mental health status examination (MMSE) and 10-item Kessler Psychological Distress Scale (K10), ${ }^{39,40}$ self-administered questionnaires. None of the participants showed any cognitive impairment in MMSE. The inclusion criteria were (i) participants who scored between 20-29 in K10 scale suggested mild-moderate mental disorders, (ii) English knowledge is mandatory to understand the instructions, (iii) both genders (male and female) participants, and (iv) only participants who are not engaged in any physical exercise (including yoga) in the previous three months.

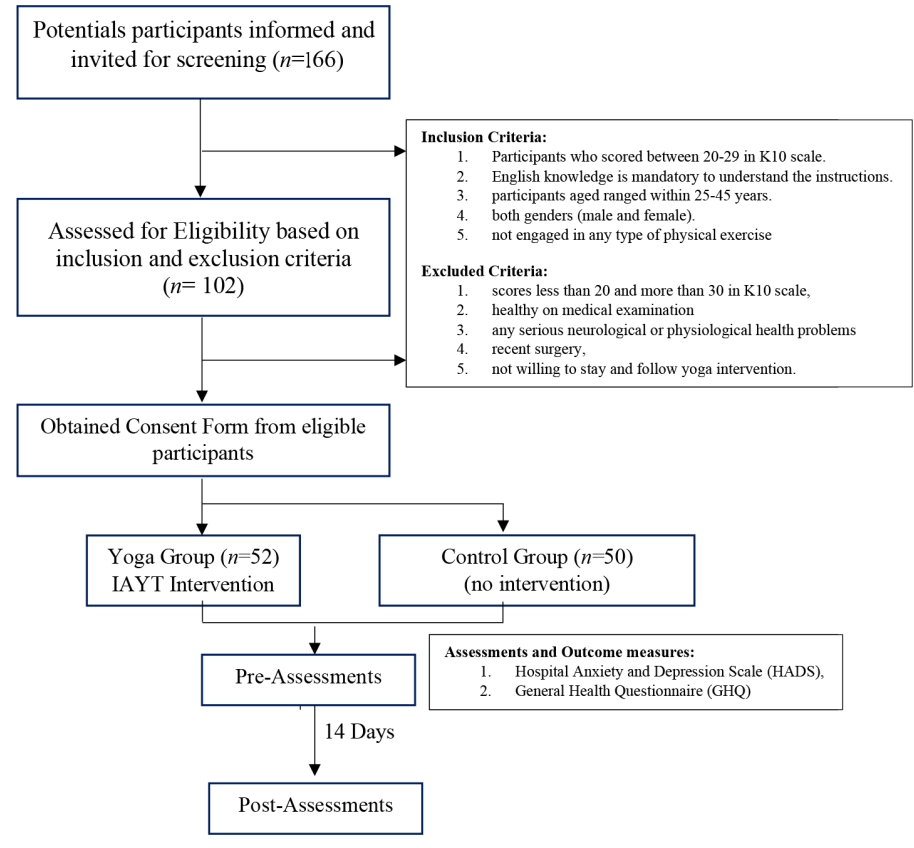

Figure 1: Expected participant's flow diagram.
The participants excluded who were (i) found scores less than 20 and more than 30 in K10 scale, (ii) healthy on medical examination, (iii) any serious neurological or physiological health problems, (iv) recent surgery, and (v) not willing to follow yoga-based lifestyle intervention. Characteristics of the participants are given in Table 1.

\section{Ethical clearance and Informed Consent}

This study was reviewed and approved by the Institutional Ethics committee a Yoga University. The design of the study and parameters were described in detail to the participants and signed informed consent was obtained. All participants were assured of the confidentiality of their data and given freedom to withdraw from the study at any point in time without explanation.

\section{Study design}

All YT participants practiced yoga for two weeks (5 days/week) and assessed with general health, anxiety, and depression before and after two-week of intervention. Another group underwent for stress and lifestyle counseling from a well-qualified and experienced counselor for the same duration. The study took place between January 2016 November 2016.

\section{Outcome measures}

(i) Socio-demographic Questionnaire

The demographic information was capture using self-prepared questionnaire consist of age, gender, marital status, religious adherence, qualification, socioeconomic status.

(ii) Psychological State.

The Hospital Anxiety and Depression Scale (HADS) was employed to investigate the psychological states of the participants. HADS scale consists of 14 items, out of that seven items related to anxiety symptoms and seven items for depression symptoms. Each item is coded from 0 to 3. The scores for anxiety and depression, the minimum score is 0 , and the maximum score is 21 , it depends on the subject present and severity of the symptoms. The score between 0 to 7 does not indicate the subject present of the symptoms of anxiety or depression, a score between 8 to 10 indicates the subject has present of the symptoms but in moderate degree, therefore doubtful case, a score greater than or equal to 11 shows that subject have significant number of symptoms of anxiety or depression corresponding to confirmed case. The internal consistency

Table 1: Demographic details of the participants are given below.

\begin{tabular}{|c|c|c|c|}
\hline S.No. & Participants & Yoga & Control \\
\hline $\begin{array}{c}\text { Total number of participants } \\
\text { (mean age in years } \pm \text { SD) }\end{array}$ & $52\left(\begin{array}{c}35.01 \pm 10.6 \\
\text { yrs })\end{array}\right.$ & $50(34.6 \pm 8.7$ \\
Grs $)$
\end{tabular}


of both subscale, i.e., anxiety and depression showed 0.80 and 0.76 , respectively. ${ }^{41}$

(iii) General Health Questionnaire (GHQ)

The 12 items of general health questionnaire (GHQ) is the most extensively used screening instrument for common mental disorders in addition to being a more general measure of psychiatric well-being. The GHQ-12 proved to be a reliable instrument, as indicated by a Cronbach's alpha of $0.81 .^{42}$ Each item coded from 0 to 4 . The scores for anxiety and depression minimum score is 0 , and the maximum score is 21 . The GHQ12 is a good measure of psychological well-being in the population and asked of half of the respondents to the Northern Ireland Health and Social Wellbeing Survey. 27.6\% respondents had a GHQ12 score of 3 or more, and $21.3 \%$ had a score of 4 or more. Women were more likely than men to have poor psychological health. Unlike the self- reported measures of health, there was no general decline in psychological well-being with age.

\section{Intervention}

YT participants underwent for two weeks yoga intervention that consists of physical exercise (posture), breathing practices (pranayama), meditation (dharana and dhyana) started from 5:30 am to 7:00 am. Yogasanas are physical postures often imitating the natural positions of the animals meant to make the mind tranquil. Yoga recognizes this link and utilizes this tool to calm down the mind. Practices include proper breathing, Kriyas and Pranayama described elsewhere. ${ }^{43}$

A direct operation on the mental level is made possible by the two limbs of Astanga Yoga of Patanjali named dharana and dhyana. The culturing of mind is accomplished by focusing on the mind (dharana) initially, followed by the relaxed dwelling of the mind in a single thought (dhyana). Progressive habituation allows the mind to remain relaxed during the period of meditation. The list of yoga practices are given in Table 2.

\section{Procedure}

The recruited participants, who had symptoms of anxiety and depression identified by the psychiatrist, were asked to fill GHQ and HADS questionnaires on $1^{\text {st }}$ day during enrolment for yoga therapy and stress lifestyle intervention. Post data were taken on the $14^{\text {th }}$ day after intervention. On $1^{\text {st }}$ day. While data collection, they were asked to sit comfortably in a common yoga hall, questionnaires and a pen distributed. Total time taken by the participants to fulfill these questionnaires were $30 \mathrm{~min}$. Similarly, after two weeks of yoga based lifestyle intervention, similar questionnaires were asked to fill the same data. Obtained data of GHQ and HADS of all participants were scored as per the stipulated instructions in the manual and then tabulated in the excel sheet.

\section{Statistical Analysis}

The obtained raw scores of HADS and GHQ were analyzed separately using SPSS version 21 (SPSS Inc., Chicago, USA). First, normality was tested using Shapiro-Wilk Test and data found normal. Therefore, paired sample t-test done between pre-post scored data and independent sample t-test was used to compare the difference between yoga and control group participants. Statistical analysis was computed at $p$-value $\leq 0.05$ with two-tailed.

\section{RESULTS}

The demographic information of all participants given in Table 1 . The paired sample t-test for anxiety and depression of HADS scores were analyzed separately. Results showed that there were significant reductions in anxiety $(p=0.04,23 \%)$ and depression $(p<0.001$, $32 \%$ ) scores after two weeks of an integrated approach of yoga therapy intervention when compared to before. The GHQ scores showed a
Table 2: List of Integrated Approach of Yoga Therapy (IAYT) practices.

\begin{tabular}{|c|c|c|}
\hline Name & Rounds & Time \\
\hline Jogging & 40 to 100 Rounds & $03 \mathrm{~min} /$ day \\
\hline Jumping & 20 to 45 rounds & $02 \mathrm{~min} /$ day \\
\hline Spinal twist & 21 to 45 rounds & $05 \mathrm{~min} /$ day \\
\hline Back swing & 11 to 45 rounds & $05 \mathrm{~min} /$ day \\
\hline Hip twist & 11 to 45 Rounds & $05 \mathrm{~min} /$ day \\
\hline Hip rotation & 11 to 45 Rounds & $05 \mathrm{~min} /$ day \\
\hline Knee stretch & 11 to 45 Rounds & $02 \mathrm{~min} /$ day \\
\hline Hip stretch-1 & 11 to 45 Rounds & $03 \mathrm{~min} /$ day \\
\hline Hip stretch -2 & 11 to 45 Rounds & $03 \mathrm{~min} /$ day \\
\hline Forward and backward bending & 11 to 45 Rounds & $02 \mathrm{~min} /$ day \\
\hline Parivrtta Trikonasana Stretch & 11 to 45 Rounds & $03 \mathrm{~min} /$ day \\
\hline Dynamic Suryanamaskara & 6 to 12 Rounds & $10 \mathrm{~min}$ \\
\hline Relax by Free walk & $30 \mathrm{~min}$ & Everyday \\
\hline Spinal stretch with legs apart & 11 Rounds & $05 \mathrm{~min}$ \\
\hline Back stretch with alternate & 11 Rounds & $05 \mathrm{~min}$ \\
\hline Back stretch with both legs & 11 Rounds & $05 \mathrm{~min}$ \\
\hline Tiger stretch & 11 Rounds & $05 \mathrm{~min}$ \\
\hline Crow walking & 11 Rounds & $05 \mathrm{~min}$ \\
\hline Dhanurasana swing & 11 Rounds & $05 \mathrm{~min}$ \\
\hline Salabhasana (both legs) & 11 Rounds & $05 \mathrm{~min}$ \\
\hline $\begin{array}{l}\text { Alternate bhujangasana and } \\
\text { parvatasana }\end{array}$ & 11 Rounds & $05 \mathrm{~min}$ \\
\hline Navasana & 11 Rounds & $05 \mathrm{~min}$ \\
\hline Crocodile walking & 11 Rounds & $05 \mathrm{~min}$ \\
\hline Quick relaxation technique & $30 \mathrm{sec}$ & $05 \mathrm{~min} /$ day \\
\hline Paschimotasana stretch & 11 Rounds & $02 \mathrm{~min}$ \\
\hline Cycling & 21 Rounds & $03 \mathrm{~min}$ \\
\hline Side leg raising (each side) & 11 Rounds & $02 \mathrm{~min} /$ day \\
\hline Alternate leg raising (each side) & 11 Rounds & $03 \mathrm{~min} /$ day \\
\hline Naukasana & 11 Rounds & $3 \min$ \\
\hline
\end{tabular}

B. Yogic cleansing practices.

\begin{tabular}{|c|c|}
\hline \multicolumn{2}{|c|}{ B. Yogic cleansing practices. } \\
\hline Cleansing practices & Rounds \\
\hline Jalaneti & Both nostril (2 times in a week) \\
\hline Sutraneti & Both sides (2 times in a week $)$ \\
\hline Vamana dhauti & Once in a week \\
\hline Laghu sankhaprakshalana & Once in a week \\
\hline Trataka & Every day for $30 \mathrm{~min}$ \\
\hline Kapalabhati & 40 to 120 strokes $/ \mathrm{min}$ \\
\hline
\end{tabular}

\section{Yogic breathing (Pranayama) and Meditation practices.}

\section{.}

\begin{tabular}{|c|c|}
\hline Pranayama & Rounds \\
\hline Vibhagiya pranayama (sectional breathing) & 5 Rounds \\
\hline Suryaanuloma viloma (4 times in a day) & 27 Round \\
\hline Nadisuddhi (4 times in a day) & 9 Rounds \\
\hline AAA chanting & 21 Rounds \\
\hline OMeditation practices & \\
\hline Cycle Meditation $(\mathrm{CM})$ & $15 \mathrm{~min}$ \\
\hline
\end{tabular}




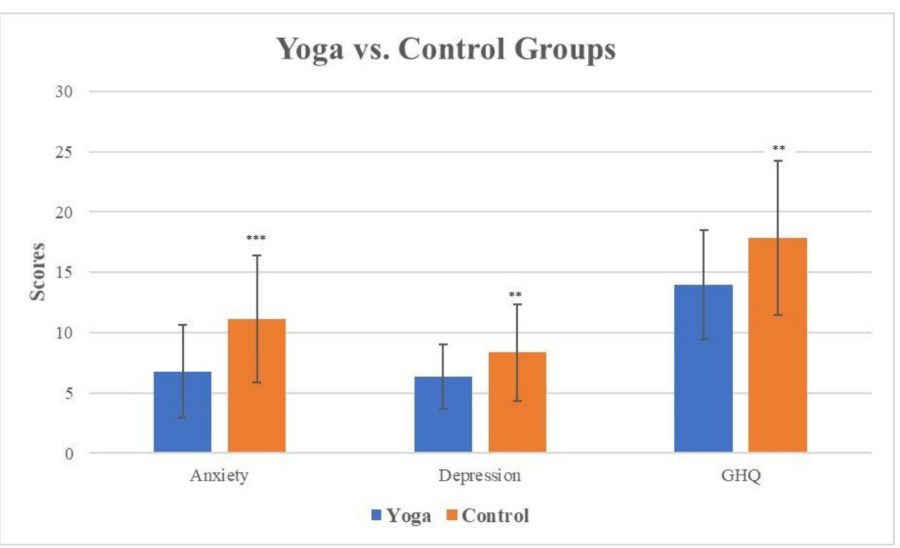

Figure 2: The comparisons between yoga and control groups in all assessments.

significant decrease the symptoms scores after yoga intervention $(p<0.01,15 \%)$ and general health improved in participants. On the other hand, control group participants reported significantly higher anxiety $(\mathrm{t}=2.09 ; p<0.05)$ compared to baseline. Independent sample $\mathrm{t}$-test was used to assess scores between-group differences. The YT group showed significantly lower anxiety (t-value $=4.76 ; p<0.001)$ and depression (t-value $=2.97 ; p<0.01)$ compared to $\mathrm{CG}$ as showed in Figure 2. Also, there was also a significant higher symptoms (GHQ) score in CG GHQ (t-value $=3.59 ; p<0.01)$.

The group means values $\pm \mathrm{SD}$, percentage change (\% change), t-value, and level of significance ( $p$-value) for anxiety and depression of HADS and GHQ are given in Table 3. In addition to this, the Pearson correlation between HADS and GHQ post data showed that there was a significantly higher association between GHQ and anxiety scores $(\mathrm{r}=0.61 ; p<0.001)$ and depression scores $(\mathrm{r}=0.41 ; p=0.004)$. Results suggest that 14 days yoga-based lifestyle practice increased association between HADS and GHQ.

\section{DISCUSSION}

Results of the present study showed decreased anxiety and depression and improved overall general health in young adults after the two-week integrated approach of yoga therapy intervention (IAYT). During yoga intervention, all participants of yoga group practiced hatha yoga postures, voluntary regulated breathing practices, Bhagavad Gita chanting, and meditation practices every day. Earlier empirical studies on each practice showed improvements in various physical and psychological problems. The physical postures (asanas) improve musculoskeletal and cardiopulmonary functions, ${ }^{44}$ the voluntary regulated breathing practices improve lung functions, ${ }^{45,46}$ balance autonomic nervous system activity $^{47,48}$ and reduced level of anxiety ${ }^{49}$ and stress-related disorders. ${ }^{30}$ Meditation helps in slowing down all mental agitation with a reduction in the distractions of mind, and that directly associated with reduced anxiety and depression. ${ }^{34,50-52}$

In the current study, the brief intervention of yoga practices showed a significant reduction in symptoms of anxiety and depression with improvement in overall health. Previous scientific investigations on integrated yoga-based intervention reported various beneficial effects in cognitive abilities, attenuation of emotional intensity, decreased anxietyrelated symptoms and salivary cortisol ${ }^{53}$ and also increased the overall quality of life for healthy individuals after six months of yoga practice..$^{54}$ Few other studies on the hyperventilating type of pranayama like kapalabhathi and bhasthrika or combination of asanas and pranayama
Table 3: The group mean values \pm SD, $t$-value, significance level ( $p$-value) for anxiety and depression of HADS.

\begin{tabular}{|c|c|c|c|c|c|c|c|}
\hline S.No. & Variable & Groups & Pre & Post & $\%$ change & $t$-value & $P$-value \\
\hline \multirow{2}{*}{1.} & \multirow{2}{*}{$\begin{array}{l}\text { Anxiety } \\
\text { HADS }\end{array}$} & Yoga & $\begin{array}{l}10.65 \\
(4.32)\end{array}$ & $\begin{array}{c}6.78 \\
(3.83)\end{array}$ & $23.38 \%$ & 3.009 & 0.04 \\
\hline & & Control & $\begin{array}{c}9.5 \\
(3.59)\end{array}$ & $\begin{array}{l}11.14 \\
(5.27)\end{array}$ & $17.26 \%$ & 2.09 & 0.039 \\
\hline \multirow{2}{*}{2.} & \multirow{2}{*}{$\begin{array}{c}\text { Depression } \\
\text { HADS }\end{array}$} & Yoga & $\begin{array}{c}9.29 \\
(3.78)\end{array}$ & $\begin{array}{c}6.33 \\
(2.66)\end{array}$ & $31.86 \%$ & 5.865 & $<0.001$ \\
\hline & & Control & $\begin{array}{c}7.8 \\
(3.12)\end{array}$ & $\begin{array}{c}8.34 \\
(4.01)\end{array}$ & $6.92 \%$ & 0.77 & NS \\
\hline \multirow{2}{*}{3.} & \multirow{2}{*}{$\begin{array}{c}\text { General } \\
\text { Health } \\
\text { Questionnaire } \\
\text { (GHQ) }\end{array}$} & Yoga & $\begin{array}{l}16.42 \\
(7.00)\end{array}$ & $\begin{array}{l}13.94 \\
(4.54)\end{array}$ & $15.10 \%$ & 2.14 & 0.03 \\
\hline & & Control & $\begin{array}{l}17.07 \\
(8.14)\end{array}$ & $\begin{array}{l}17.86 \\
(6.38)\end{array}$ & $4.63 \%$ & 0.55 & NS \\
\hline
\end{tabular}

reported positive effects on anxiety and depression levels..$^{27}$ The practice of mindfulness-based meditation has been shown to diminish the habitual tendency to emotionally react to and ruminate about transitory thoughts and physical sensations and improves psychological health by reducing stress, depression and anxiety symptoms with improvement in behavioral self-regulation and improved volitional orientating of attention. ${ }^{55}$ Similarly, participants who practice regular yoga, pranayama, and mindful meditation, that may enhance emotional regulation with a reduction in momentary thoughts may be a key factor to reduce anxiety and depression as shown in the present study. These studies suggest yoga practices helps in improvement of awareness, regulate mind, emotions and the responses in adverse condition. ${ }^{54,56,57}$ But how yoga affects anxiety and depression is not fully know. This paper attempts to present a hypothetical mechanism of yoga practices associated with changes in anxiety and depression.

Brain imaging studies reported that the panic anxiety is associated with decreased regional cerebral blood flow ( $\mathrm{rCBF})$ in the right orbitofrontal (Brodmann area 11), prelimbic (area 25), anterior cingulate (area 32) and anterior temporal cortices (area 15). ${ }^{58}$ Few neuroimaging studies explored the neural correlates of meditation-related anxiety relief was associated with activation of the anterior cingulate cortex, ventromedial prefrontal cortex and anterior insula. ${ }^{59}$ It was observed that, during meditation, those who exhibited greater default-related activity (i.e., posterior cingulate cortex) reported greater anxiety, possibly reflecting an inability to control self-referential thoughts. The above-mentioned studies suggest that mindfulness meditation attenuates anxiety through mechanisms involved in the regulation of self-referential thought processes.

The yoga-based lifestyle intervention consisted of postures, voluntary regulated breathing practices and meditation influence metabolism, autonomic nervous system, higher brain functions, and mental state ${ }^{60-62}$ and may modulate anxiety and depression. Yoga postures and breathing practices increase rhythmic activity, mechanoreceptors sensitivity of connective tissue, muscular fibers and skeletal muscles. ${ }^{63,64}$ The muscular movements while postures and pranayama stimulate various receptors at different joints, intrafusal, exteroceptive and interoceptors. ${ }^{65-67}$ The smooth and skeletal muscle fibers are innervated by large, myelinated nerve fibers that originate from large motorneurons in the anterior horns of the spinal cord. ${ }^{63}$ Each nerve fiber ending makes a junction called neuromuscular junction that receives sensory impulses from muscles movements and stretches that stimulate various neurotransmitters such as Acetylcholine (Ach), ${ }^{68}$ norepinephrine (NA) and serotonin (5-HT) from brainstem. ${ }^{69,70}$ While voluntary movements, norepinephrine (NA) 
release from nucleus locus coeruleus (LC) which has excitatory effects, whereas serotonin releases from dorsal raphe nucleus of brainstem have an inhibitory effect on the paraventricular nucleus that may regulate autonomic nervous system (ANS) activity. ${ }^{71}$ The regular aerobic exercises (such as yoga and Tai-Chi) showed the stimulation of pressure receptors leading to increased vagal activity, decreased stress hormones and increased production of anti-pain and antidepressant neurotransmitters such as serotonin. ${ }^{72}$ On the other hand, Ach also released from the skeletal muscles that stimulate preganglionic neurons of ANS, and postganglionic neurons of parasympathetic and sympathetic nervous system. ${ }^{73}$ The Ach may play a very important role in autonomic nervous system activity to regulate cyclic regulation of sympathetic and parasympathetic activity by yoga postures and breathing practices. These neurotransmitters stimulate hypothalamic nuclei to release corticotrophin-releasing hormones $(\mathrm{CRH})$, an important neurotransmitter to balance hypothalamicpituitary-adrenal axis (HPA). ${ }^{74,75}$ The main neurotransmitter from HPA is adrenocortical releasing hormone (ACTH) from the pituitary gland and regulated the activities in basal ganglia, thalamus, hippocampus and amygdala. ${ }^{76-78}$ The amygdala is a most important limbic structure that receives sensory information and project to other subcortical structures, thereby mediating stress-related behavioral and physiological effects. The amygdala stimulation can cause several types of involuntary movements such as tonic movements of head or body raising or bending, circling movements, etc. ${ }^{79-82}$ The regulation activities of the thalamus and cerebral cortex, the main neurotransmitter is GABA, an inhibitory neurotransmitter. ${ }^{83}$ A previous study findings demonstrated that in experienced yoga practitioners, brain GABA levels increase after a session of yoga ${ }^{84}$ suggest, regular yoga practices for 60 min may be as a treatment for disorders with low GABA levels such as depression and anxiety disorders. This suggest the anxiolytic effect of yoga based lifestyle intervention that may occur by promotion of an inhibitory tone in specific areas of the brain. ${ }^{85-90}$ as described in Figure 3.

This cortical inhibition may enhance the cerebral cortex functioning specially in the anterior cingulate cortex (ACC), dorsal medial prefrontal cortex (DMPC), sensory and motor cortex..$^{91-94}$ This improvements in the functioning of brainstem, thalamic activity and cerebral cortex may help to reduce the symptoms of anxiety and depression in humans. Studies have shown that yoga postures with interspersed breathing activity reported enhanced regulation in autonomic nervous system (ANS) modulation also called "sympathovagal balance". ${ }^{95-97}$ The yoga posture with awareness reduced stress and may help to regulate and balance hypothalamic-pituitary-adrenal axis (HPA). A review article reported physical and mental health benefits of yoga via down-regulation of the hypothalamic-pituitary-adrenal (HPA) axis and the sympathetic nervous system (SNS). ${ }^{98}$

Regular body-mind intervention may be associated with a reduction in psychological stress as showed in plasma catecholamine, i.e., decreased norepinephrine with increased epinephrine and dopamine and higher positive effect. ${ }^{99} \mathrm{~A}$ review article on mindfulness meditation effect on mental and physical health reported that the mindfulness practice is associated with increased well-being as well as reduced cognitive reactivity and behavioral avoidance. ${ }^{100,101}$ In addition, mindfulness meditation may contribute to enhance immune functions, diminish inflammation, diminish the reactivity of the autonomic nervous system (ANS), increase telomerase activity, lead to higher levels of plasmatic melatonin and serotonin. ${ }^{102}$ The summarized mechanism of yoga based lifestyle intervention on anxiety and depression depicted in Figure 4. Few other studies have been shown the social interaction ${ }^{103}$ and environmental influences ${ }^{104}$ are largely time-specific and contribute to change in symptoms of anxiety and depression as well. Moreover, the present study described yoga would be devised as an effective alternative

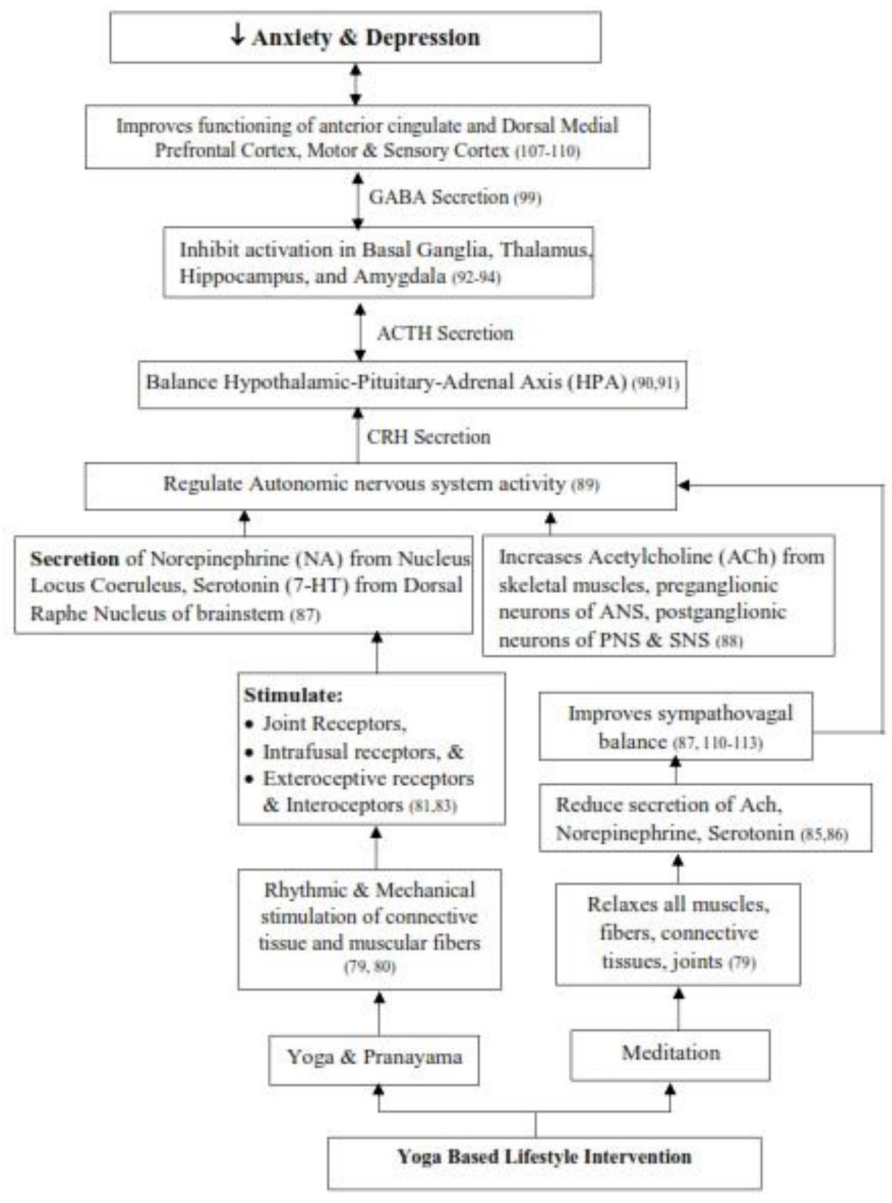

Figure 3: Hypothetical mechanisms of the effect of yoga practices in reducing anxiety and depression.

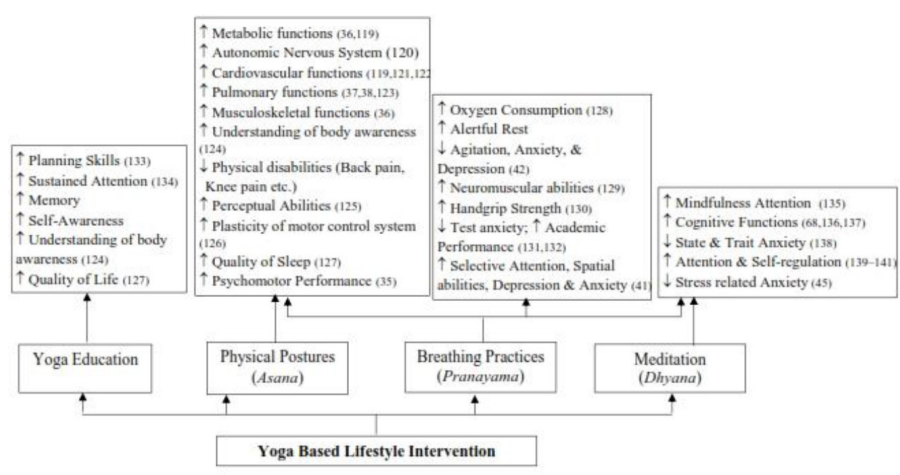

Figure 4: Summarized effect of different components of yoga based lifestyle intervention on physical, mental and social health.

to drugs for the treatment of anxiety and depression in young adults and older people.

In summary, the present study showed yoga-based lifestyle intervention has a positive effect on symptoms of anxiety and depression in young adults. The lowered anxiety and depression was observed in HADS measurement scale, and improvement in overall general health wellbeing in GHQ scale after 14 days intense practice of yoga-based lifestyle intervention in a yoga center. Further, although young adult participants 
showed significant improvement across all the domains (anxiety, depression and general health wellbeing) after the intervention, a followup study with active control group comparison with home-based yoga intervention program should be worth exploring in future studies. There were major limitations of this study like it was a small sample size, no randomization, and no follow-up data acquired. There were no any physiological or neurophysiological assessments done to cross-validate the effect of yoga based lifestyle intervention on anxiety and depression. Also, additional electrophysiological and neuroimaging researchers are needed to explore the mechanism of the beneficial effect of yoga based lifestyle intervention in and out patient's yoga center on anxiety and depression.

\section{CONCLUSION}

Yoga-based lifestyle intervention showed a significant reduction in the symptoms of anxiety and depression with increased overall general health wellbeing. This study may help to develop a yoga-based lifestyle environment/culture in practitioner's home that may enhance the coping capabilities from day to day stress in life. The yoga-based lifestyle study may facilitate healthy living at home (strengthen interpersonal and intrapersonal relationships), improves neighboring hood, and grow a happy and healthy society.

\section{ACKNOWLEDGEMENT}

The present study was supported by Department of Yoga and Life Sciences, Swami Vivekananda Yoga Anusandhana Samsthana (S-VYASA), Bangalore, India is gratefully acknowledged.

\section{CONFLICT OF INTEREST}

The authors declare that there is no conflict of interest.

\section{REFERENCES}

1. Rohrer JE, Pierce JR, Blackburn C. Lifestyle and mental health. Prev Med. 2005;40(4):438-43. doi: 10.1016/j.ypmed.2004.07.003, PMID 15530596.

2. Scott D, Happell B. The high prevalence of poor physical health and unhealthy lifestyle behaviours in individuals with severe mental illness. Issues Ment Health Nurs. 2011;32(9):589-97. doi: 10.3109/01612840.2011.569846, PMID 21859410.

3. Byrd DR, McKinney KJ. Individual, interpersonal, and institutional level factors associated with the mental health of college students. J Am Coll Health. 2012;60(3):185-93. doi: 10.1080/07448481.2011.584334, PMID 22420695.

4. Patel V, Flisher AJ, Hetrick S, McGorry P. Mental health of young people: A global public-health challenge. Lancet. 2007;369(9569):1302-13. doi: 10.1016/ S0140-6736(07)60368-7, PMID 17434406

5. De CM. Role of social media in tackling challenges in mental health Proceedings of the $2^{\text {nd }}$ interface work sociaal Multimed. Vols. 49-52; 2013. doi: 10.1145/2509916.2509921.

6. Coleman JC (James C. Butcher JN, Carson RC. Abnormal psychology and modern life. Illinois. Scott: Foresman, and Company; 1980.

7. Murphy JM, Leighton AH. Anxiety: Its role in the history of psychiatric epidemiology. Psychol Med. 2009;39(7):1055-64. doi: 10.1017/ S0033291708004625, PMID 18940025

8. Reddy PD, Thirumoorthy A, Vijayalakshmi P, Hamza MA. Effectiveness of solution-focused brief therapy for an adolescent girl with moderate depression. Indian J Psychol Med. 2015;37(1):87-9. doi: 10.4103/0253-7176.150849, PMID 25722519.

9. Phimarn W, Kaewphila P, Suttajit S, Saramunee K. Depression screening and advisory service provided by community pharmacist for depressive students in university. Springerplus. 2015;4:470. doi: 10.1186/s40064-015-1259-1, PMID 26357601.

10. Jamison DT, Shahid-Salles SA, Jamison J, Lawn JE, Zupan J. Incorporating deaths near the time of birth into estimates of the global burden of disease; 2006.

11. Eisenberg D, Hunt J, Speer N. Mental health in American colleges and universities: Variation across student subgroups and across campuses. J Nerv Ment Dis. 2013;201(1):60-7. doi: 10.1097/NMD.0b013e31827ab077, PMID 23274298.

12. Kumar KS, Akoijam BS. Depression, anxiety and stress among higher secondary school students of Imphal, Manipur. Indian J Community Med 2017;42(2):94-6. doi: 10.4103/ijcm.IJCM_266_15, PMID 28553025.

13. Kim EH, Coumar A, Lober WB, Kim Y. Addressing mental health epidemic among university students via web-based, self-screening, and referral system: A preliminary study. IEEE Trans Inf Technol Biomed. 2011;15(2):301-7. doi: 10.1109/TITB.2011.2107561, PMID 21257386

14. Burns JL, Lee RM, Brown LJ.The effect of meditation on self-reported measures of stress, anxiety, depression, and perfectionism in a college population. J Coll Stud Psychother. 2011;25(2):132-44. doi: 10.1080/87568225.2011.556947.

15. Edenfield TM, Saeed SA. An update on mindfulness meditation as a self-help treatment for anxiety and depression. Psychol Res Behav Manag. 2012;5:131 41. doi: 10.2147/PRBM.S34937, PMID 23175619.

16. Leite JR, Ornellas FLDM, Amemiya TM, De Almeida AA, Dias AA, Afonso R, et al. Effect of progressive self-focus meditation on attention, anxiety, and depression scores. Percept Mot Skills. 2010;110(3 Pt 1):840-8. doi: 10.2466/ PMS.110.3.840-848, PMID 20681336

17. Srivastava M, Talukdar U, Lahan V. Meditation for the management of adjustment disorder anxiety and depression. Complement Ther Clin Pract. 2011;17(4):241-5. doi: 10.1016/j.ctcp.2011.04.007, PMID 21982141.

18. Wang F, Lee EK, WuT, Benson H, Fricchione G, Wang W, et al. The effects of tai chi on depression, anxiety, and psychological well-being: A systematic review and meta-analysis. Int J Behav Med. 2014;21(4):605-17. doi: 10.1007/s12529 013-9351-9, PMID 24078491

19. FieldT, Diego M, Delgado J, Medina L. Tai chi/yoga reduces prenatal depression, anxiety and sleep disturbances. Complement Ther Clin Pract. 2013;19(1):6-10. doi: 10.1016/j.ctcp.2012.10.001, PMID 23337557.

20. Zhang J, Qin S, Zhou Y, Meng L, Su H, Zhao S. A randomized controlled trial of mindfulness-based Tai Chi Chuan for subthreshold depression adolescents. Neuropsychiatr Dis Treat. 2018;14:2313-2321.

21. Chow YWY, Dorcas A, Siu AMH. The effects of Qigong on Reducing stress and anxiety and enhancing body-mind well-being. Mindfulness (N Y). 2012;3(1):51-9. doi: 10.1007/s12671-011-0080-3.

22. Johansson M, Hassmén P, Jouper J. Acute effects of Qigong exercise on mood and anxiety. SportExerc Perform Psychol. 2011:1(S):60-5. doi: 10.1037/21573905.1.S.60.

23. Wang F, Man JKM, Lee EKO, Wu T, Benson H, Fricchione GL, Wang W, Yeung A. The effects of qigong on anxiety, depression, and psychological well-being: A systematic review and meta-analysis. Evid Based Complement Alternat Med. 2013;2013:152738. doi: 10.1155/2013/152738, PMID 23401706.

24. Javnbakht M, Hejazi Kenari R, Ghasemi M. Effects of yoga on depression and anxiety of women. Complement Ther Clin Pract. 2009;15(2):102-4. doi 10.1016/j.ctcp.2009.01.003, PMID 19341989

25. Skowronek IB, Mounsey A, Handler L. Clinical Inquiry: Can yoga reduce symptoms of anxiety and depression? J Fam Pract. 2014;63(7):398-407. PMID 25198206

26. Woolery A, Myers H, Sternlieb B, Zeltzer L. A yoga intervention for young adults with elevated symptoms of depression. Altern Ther Health Med. 2004;10(2):60-3. PMID 15055096.

27. Saeed SA, Antonacci DJ, Bloch RM. Exercise, yoga, and meditation for depressive and anxiety disorders. Am Fam Physician. 2010;81(8):981-6. PMID 20387774

28. Singh D, Suhas A, Naveen K, Nagendra $H$. Measures of mindfulness and anxiety in OM meditators and non-meditators: A cross-sectional study. Int J Med Public Health. 2014;4(1):110. doi: 10.4103/2230-8598.127170.

29. Flegal KE, Kishiyama S, Zajdel D, Haas M, Oken BS. Adherence to yoga and exercise interventions in a 6-month clinical trial. BMC Complement Altern Med. 2007;7:37. doi: 10.1186/1472-6882-7-37, PMID 17996075.

30. Brown RP, Gerbarg PL. Sudarshan Kriya yogic breathing in the treatment of stress, anxiety, and depression: part I-neurophysiologic model. J Altern Complement Med. 2005;11(1):189-201. doi: 10.1089/acm.2005.11.189, PMID 15750381.

31. Brown RP, Gerbarg PL. Sudarshan Kriya Yogic breathing in the treatment of stress, anxiety, and depression. part II--Clinical applications and guidelines. J Altern Complement Med. 2005;11(4):711-7. doi: 10.1089/acm.2005.11.711, PMID 16131297.

32. Zope SA, Zope RA. Sudarshan kriya yoga: breathing for health. Int J Yoga 2013;6(1):4-10. doi: 10.4103/0973-6131.105935, PMID 23440614.

33. Jorm AF Morgan AJ, Hetrick SE. Relaxation for depression. Cochrane Database Syst Rev. 2008;2(4):CD007142. doi: 10.1002/14651858.CD007142. pub2, PMID 18843744

34. Chen $Y$, Yang $X$, Wang $L$, Zhang $X$. A randomized controlled trial of the effects of brief mindfulness meditation on anxiety symptoms and systolic blood pressure in Chinese nursing students. Nurse Educ Today. 2013:33(10):1166-72 doi: 10.1016/j.nedt.2012.11.014, PMID 23260618.

35. Goldin PR, Gross JJ. Effects of mindfulness-based stress reduction (MBSR) on emotion regulation in social anxiety disorder. Emotion. 2010;10(1):83-91. doi: 10.1037/a0018441, PMID 20141305

36. Sharma VK, Das S, Mondal S, Goswami U, Gandhi A. Effect of Sahaj Yoga on neuro-cognitive functions in patients suffering from major depression. Indian J Physiol Pharmacol. 2006;50(4):375-83. PMID 17402267. 
37. Manocha R, Black D, Sarris J, Stough C. A randomized, controlled trial of meditation for work stress, anxiety and depressed mood in full-time workers. Evid Based Complement Alternat Med. 2011;2011:960583. doi: 10.1155/2011/960583.

38. Brown RP, Gerbarg PL. Yoga breathing, meditation, and longevity. Ann N Y Acad Sci. 2009:1172:54-62. doi: 10.1111/j.1749-6632.2009.04394.X. PMID 19735239.

39. Kessler RC, Andrews G, Colpe LJ, Hiripi E, Mroczek DK, Normand SL, Walters EE, Zaslavsky AM. Short screening scales to monitor population prevalences and trends in non-specific psychological distress. Psychol Med. 2002:32(6):959-76. doi: 10.1017/s0033291702006074, PMID 12214795.

40. Andrews G, Slade T. Interpreting scores on the Kessler Psychological Distress Scale (K10). Aust N Z J Public Health. 2001;25(6):494-7. doi: 10.1111/j.1467842x.2001.tb00310.x, PMID 11824981.

41. Mykletun A, Stordal E, Dahl AA. Hospital Anxiety and Depression (HAD) scale: factor structure, item analyses and internal consistency in a large population. Br J Psychiatry. 2001;179:540-4. doi: 10.1192/bjp.179.6.540, PMID 11731359.

42. Politi PL, Piccinelli M, Wilkinson G. Reliability, validity and factor structure of the 12-item General Health Questionnaire among young males in Italy. Acta Psychiatr Scand. 1994;90(6):432-7. doi: 10.1111/j.1600-0447.1994.tb01620.x, PMID 7892776.

43. Das M, Deepeshwar S, Subramanya P, Manjunath NK. Influence of YogaBased Personality Development Program on Psychomotor Performance and Self-efficacy in School Children. Front Pediatr. 2016;4:62. doi: 10.3389/ fped.2016.00062, PMID 27379220.

44. Raub JA. Psychophysiologic effects of Hatha yoga on musculoskeletal and cardiopulmonary function: a literature review. J Altern Complement Med. 2002;8(6):797-812. doi: 10.1089/10755530260511810, PMID 12614533.

45. Karthik PS, Chandrasekhar M, Ambareesha K, Nikhil C. Effect of pranayama and suryanamaskar on pulmonary functions in medical students. J Clin Diagn Res. 2014;8(12):BC04-6. doi: 10.7860/JCDR/2014/10281.5344, PMID 25653936.

46. Bezerra LA, de Melo HF, Garay AP, Reis VM, Aidar FJ, Bodas AR, Garrido ND, de Oliveira RJ. Do 12-week yoga program influence respiratory function of elderly women? J Hum Kinet. 2014:43:177-84. doi: 10.2478/hukin-2014-0103, PMID 25713658

47. Raghuraj $P$, Telles S. Immediate effect of specific nostril manipulating yoga breathing practices on autonomic and respiratory variables. Appl Psychophysio Biofeedback. 2008;33(2):65-75. doi: 10.1007/s10484-008-9055-0, PMID 18347974.

48. Upadhyay Dhungel K, Malhotra V, Sarkar D, Prajapati R. Effect of alternate nostril breathing exercise on cardiorespiratory functions. Nepal Med Coll J. 2008;10(1):25-7. PMID 18700626

49. Marshall RS, Basilakos A, Williams T, Love-Myers K. Exploring the benefits of unilateral nostril breathing practice post-stroke: attention, language, spatia abilities, depression, and anxiety. J Altern Complement Med. 2014;20(3):185-94. doi: 10.1089/acm.2013.0019, PMID 24116880

50. Sears S, Kraus S. I think therefore I om: cognitive distortions and coping style as mediators for the effects of mindfulness meditation on anxiety, positive and negative affect, and hope. J Clin Psychol. 2009;65(6):561-73. doi: 10.1002 jclp.20543, PMID 19241400.

51. Vahia VN, Shetty HK, Motiwala S, Thakkar G, Fernandes L, Sharma JC Efficacy of meditation in generalized anxiety disorder. Indian J Psychiatry. 1993:35(2):87-91. PMID 21743608.

52. Brown RP, Gerbarg PL. Sudarshan Kriya Yogic breathing in the treatment of stress, anxiety, and depression. Part II--clinical applications and guidelines. J Altern Complement Med. 2005;11(4):711-7. doi: 10.1089/acm.2005.11.711, PMID 16131297.

53. Hannesdóttir, Ollendick. Self-efficacy and social anxiety. Int J Psychol. 2007;4(2):133-8.

54. Rocha KKF, Ribeiro AM, Rocha KCF, Sousa MB, Albuquerque FS, Ribeiro S, Silva $\mathrm{RH}$. Improvement in physiological and psychological parameters after 6months of yoga practice. Conscious Cogn. 2012;21(2):843-50. doi: 10.1016/j. concog.2012.01.014, PMID 22342535.

55. Ramel W, Goldin PR, Carmona PE, McQuaid JR. The Effects of Mindfulness Meditation on Cognitive Processes and Affect in Patients with Past Depression. Cognit Ther Res. 2004;28(4):433-455. doi:10.1023/ B:COTR.0000045557.15923.96

56. Evans S, Cousins L, Tsao JCl, Sternlieb B, Zeltzer LK. Protocol for a randomized controlled study of lyengar yoga for youth with irritable bowel syndrome. Trials. 2011;12:15. doi: 10.1186/1745-6215-12-15, PMID 21244698

57. Monk-Turner E, Turner C. Does yoga shape body, mind and spiritual health and happiness: differences between yoga practitioners and college students. Int $J$ Yoga. 2010;3(2):48-54. doi: 10.4103/0973-6131.72630, PMID 21170230.

58. Fischer $H$, Andersson JLR, Furmark T, Fredrikson M. Brain correlates of an unexpected panic attack: A human positron emission tomographic study. Neurosci Lett. 1998:251(2):137-40. doi: 10.1016/s0304-3940(98)00503-5, PMID 9718993

59. Zeidan F, Martucci KT, Kraft RA, McHaffie JG, Coghill RC. Neural correlates of mindfulness meditation-related anxiety relief. Soc Cogn Affect Neurosci.
2014;9(6):751-9. doi: 10.1093/scan/nst041, PMID 23615765

60. Telles S, Singh N. Science of the mind: ancient yoga texts and modern studies Psychiatr Clin North Am. 2013;36(1):93-108. doi: 10.1016/j.psc.2013.01.010 PMID 23538080

61. Enaw JO, Smith AK. Biomarker Development for Brain-Based Disorders: Recent Progress in Psychiatry. J Neurol Psychol. 2013;1(2):7. doi: 10.13188/23323469.1000006. PMID 25110721.

62. Telles S, Deepeshwar S, Naveen KV, Pailoor S. Long latency auditory evoked potentials during meditation. Clin EEG Neurosci. 2015;46(4):299-309. doi: 10.1177/1550059414544737, PMID 25380593.

63. McArdle WD, Katch FI, Katch VL. Exercise physiology: nutrition, energy, and human performance. Lippincott Williams and Wilkins; 2010

64. Haouzi P, Chenuel B, Huszczuk A. Sensing vascular distension in skeletal muscle by slow conducting afferent fibers: neurophysiological basis and implication for respiratory control. J Appl Physiol (1985). 2004;96(2):407-18. doi: 10.1152/japplphysiol.00597.2003, PMID 14715672.

65. Fortier S, Basset FA. The effects of exercise on limb proprioceptive signals. $J$ Electromyogr Kinesiol. 2012;22(6):795-802. doi: 10.1016/j.jelekin.2012.04.001 PMID 22579804

66. Proske U, Gandevia SC. The proprioceptive senses: their roles in signaling body shape, body position and movement, and muscle force. Physiol Rev. 2012;92(4):1651-97. doi: 10.1152/physrev.00048.2011, PMID 23073629.

67. Marek SM, Cramer JT, Fincher AL, Massey LL, Dangelmaier SM, Purkayastha S, Fitz KA, Culbertson JY. Acute effects of static and proprioceptive neuromuscular facilitation stretching on muscle strength and power output. J Athl Train. 2005;40(2):94-103. doi: 10.1016/S0162-0908(08)70360-X, PMID 15970955.

68. Goto C, Higashi Y, Kimura M, Noma K, Hara K, Nakagawa K, Kawamura M, Chayama K, Yoshizumi M, Nara I. Effect of different intensities of exercise on endothelium-dependent vasodilation in humans: role of endotheliumdependent nitric oxide and oxidative stress. Circulation. 2003;108(5):530-5. doi: 10.1161/01.CIR.0000080893.55729.28, PMID 12874192.

69. Ashalatha PR, Deepa G. Textbook of anatomy and physiology for nurses. jay pee brothers. Medical Publishers Pvt, Limited; 2012.

70. Hall JE. Guyton and Hall textbook of medical physiology Elsevieron VitalSource. Elsevier Health Sciences; 2015

71. Singh $\mathrm{K}$, Bhargav $\mathrm{H}$, Srinivasan TM. Effect of uninostril yoga breathing on brain hemodynamics: A functional near-infrared spectroscopy study. Int J Yoga. 2016;9(1):12-9. doi: 10.4103/0973-6131.171711, PMID 26865766.

72. Field T. Exercise research on children and adolescents. Complement Ther Clin Pract. 2012;18(1):54-9. doi: 10.1016/j.ctcp.2011.04.002, PMID 22196575

73. Martini FEA. Anatomy and physiology. 2007. Editi. Rex Bookstore, Inc

74. Yanagita S, Amemiya S, Suzuki S, Kita I. Effects of spontaneous and forced running on activation of hypothalamic corticotropin-releasing hormone neurons in rats. Life Sci. 2007;80(4):356-63. doi: 10.1016/j.Ifs.2006.09.027, PMID 17067638

75. Kraemer RR, Blair S, Kraemer GR, Castracane VD. Effects of treadmill running on plasma beta-endorphin, corticotropin, and cortisol levels in male and female 10K runners. Eur J Appl Physiol Occup Physiol. 1989;58(8):845-51. doi: 10.1007/BF02332217, PMID 2548864.

76. Bennett MR. The prefrontal-limbic network in depression: modulation by hypothalamus, basal ganglia and midbrain. Prog Neurobiol. 2011;93(4):468-87. doi: 10.1016/j.pneurobio.2011.01.006, PMID 21349315.

77. Aguilera G. HPA axis responsiveness to stress: implications for healthy aging. Exp Gerontol. 2011:46(2-3):90-5. doi: 10.1016/j.exger.2010.08.023, PMID 20833240.

78. Herman JP, Ostrander MM, Mueller NK, Figueiredo H. Limbic system mechanisms of stress regulation: hypothalamo-pituitary-adrenocortical axis. Prog Neuropsychopharmacol Biol Psychiatry. 2005;29(8):1201-13. doi: 10.1016/j.pnpbp.2005.08.006, PMID 16271821.

79. Petit L, Beauchamp MS. Neural basis of visually guided head movements studied with fMRI. J Neurophysiol. 2003;89(5):2516-27. doi: 10.1152/ jn.00988.2002, PMID 12611944

80. Cowie RJ, Robinson DL. Subcortical contributions to head movements in macaques. I. Contrasting effects of electrical stimulation of a medial pontomedullary region and the superior colliculus. J Neurophysiol. 1994;72(6):2648-64. doi: 10.1152/jn. 1994.72.6.2648, PMID 7897481.

81. Rassler B, Raabe J. Co-ordination of breathing with rhythmic head and eye movements and with passive turnings of the body. Eur J Appl Physiol. 2003;90(1-2):125-30. doi: 10.1007/s00421-003-0876-5, PMID 12827368.

82. Chen LL, Tehovnik EJ. Cortical control of eye and head movements: integration of movements and percepts. Eur J Neurosci. 2007;25(5):1253-64. doi: 10.1111/j.1460-9568.2007.05392.x, PMID 17425554.

83. Herman JP, Mueller NK, Figueiredo $H$. Role of GABA and glutamate circuitry in hypothalamo-pituitary- adrenocortical stress integration. Ann NY Acad Sci. 2004:1018:35-45. doi: 10.1196/annals.1296.004, PMID 15240350.

84. Streeter CC, Jensen JE, Perlmutter RM, Cabral HJ, Tian H, Terhune DB, Ciraulo DA, Renshaw PF. Yoga Asana sessions increase brain GABA levels: a pilot study. Altern Complement Med. Yoga Asana sessions increase brain GABA levels: pilot study. 2007;13(4):419-26. doi: 10.1089/acm.2007.6338, PMID 17532734. 
85. Kask A, Harro J, von Hörsten S, Redrobe JP, Dumont Y, Quirion R. The neurocircuitry and receptor subtypes mediating anxiolytic-like effects of neuropeptide Y. Neurosci Biobehav Rev. 2002;26(3):259-83. doi: 10.1016/ s0149-7634(01)00066-5, PMID 12034130.

86. Rubino T, Guidali C, Vigano D, Realini N, Valenti M, Massi P, Parolaro D. CB1 receptor stimulation in specific brain areas differently modulate anxietyrelated behaviour. Neuropharmacology. 2008;54(1):151-60. doi: 10.1016/j. neuropharm.2007.06.024, PMID 17692344.

87. Sanders RD. Hypothesis for the pathophysiology of delirium: role of baseline brain network connectivity and changes in inhibitory tone. Med Hypotheses. 2011;77(1):140-3. doi: 10.1016/j.mehy.2011.03.048, PMID 21498007.

88. Pilkington K, Kirkwood G, Rampes $H$, Richardson J. Yoga for depression: the research evidence. J Affect Disord. 2005;89(1-3):13-24. doi: 10.1016/j. jad.2005.08.013, PMID 16185770.

89. Descilo T, Vedamurtachar A, Gerbarg PL, Nagaraja D, Gangadhar BN, Damodaran B, Adelson B, Braslow LH, Marcus S, Brown RP. Effects of a yoga breath intervention alone and in combination with an exposure therapy for post-traumatic stress disorder and depression in survivors of the 2004 South-East Asia tsunami. Acta Psychiatr Scand. 2010;121(4):289-300. doi: 10.1111/j.1600-0447.2009.01466.x, PMID 19694633.

90. Desai R, Tailor A, Bhatt T. Effects of yoga on brain waves and structural activation: a review. Complement Ther Clin Pract. 2015;21(2):112-8. doi: 10.1016/j.ctcp.2015.02.002, PMID 25824030.

91. Braver TS, Barch DM, Gray JR, Molfese DL, Snyder A. Anterior cingulate cortex and response conflict: effects of frequency, inhibition and errors. Cereb Cortex. 2001;11(9):825-36. doi: 10.1093/cercor/11.9.825, PMID 11532888.

92. Heidbreder CA, Groenewegen HJ. The medial prefrontal cortex in the rat: evidence for a dorso-ventral distinction based upon functional and anatomical characteristics. Neurosci Biobehav Rev. 2003;27(6):555-79. doi: 10.1016/j. neubiorev.2003.09.003, PMID 14599436.

93. Ongür $\mathrm{D}$, Price JL. The organization of networks within the orbital and medial prefrontal cortex of rats, monkeys and humans. Cereb Cortex. 2000;10(3):206-19. doi: 10.1093/cercor/10.3.206, PMID 10731217.

94. Etkin A, Egner T, Kalisch R. Emotional processing in anterior cingulate and medial prefrontal cortex. Trends Cogn Sci. 2011;15(2):85-93. doi: 10.1016/j. tics.2010.11.004, PMID 21167765.

95. Pal G. Yoga and heart rate variability. Int J Clin Exp Physiol. 2015;2(1):2. doi: 10.4103/2348-8093.155502.

96. Goldberger JJ. Sympathovagal balance: How should we measure it? Am J Physiol. 1999;276(4 Pt 2):H1273-80. doi: 10.1152/ajpheart.1999.276.4.H1273, PMID 10199852.

97. Santaella DF, Devesa CRS, Rojo MR, Amato MB, Drager LF, Casali KR, Montano N, Lorenzi-Filho G. Yoga respiratory training improves respiratory function and cardiac sympathovagal balance in elderly subjects: A randomised controlled trial. BMJ Open. 2011;1(1):e000085. doi: 10.1136/ bmjopen-2011-000085, PMID 22021757.

98. Ross A, Thomas S. The health benefits of yoga and exercise: A review of comparison studies. J Altern Complement Med. 2010;16(1):3-12. doi: 10.1089/ acm.2009.0044, PMID 20105062.

99. Jung YH, Kang DH, Jang JH, Park HY, Byun MS, Kwon SJ, et al. The effects of mind-body training on stress reduction, positive affect, and plasma catecholamines. Neurosci Lett. 2010;479(2):138-42. doi: 10.1016/j. neulet.2010.05.048, PMID 20546836.

100. Keng SL, Smoski MJ, Robins CJ. Effects of mindfulness on psychological health: A review of empirical studies. Clin Psychol Rev. 2011;31(6):1041-56. doi: 10.1016/j.cpr.2011.04.006, PMID 21802619.

101. Krygier JR, Heathers JAJ, Shahrestani S, Abbott M, Gross JJ, Kemp AH. Mindfulness meditation, well-being, and heart rate variability: A preliminary investigation into the impact of intensive vipassana meditation. Int $\mathrm{J}$ Psychophysiol. 2013;89(3):305-313.

102. Ngô TL. [Review of the effects of mindfulness meditation on mental and physical health and its mechanisms of action]. S Ment Que. 2013;38(2):19-34. doi: 10.7202/1023988ar, PMID 24719001.

103. Cohen S. Social relationships and health. Am Psychol. 2004;59(8):676-84. doi: 10.1037/0003-066X.59.8.676, PMID 15554821.

104. Waszczuk MA, Zavos HMS, Gregory AM, Eley TC. The stability and change of etiological influences on depression, anxiety symptoms and thei co-occurrence across adolescence and young adulthood. Psychol Med. 2016;46(1):161-75. doi: 10.1017/S0033291715001634, PMID 26310536. 